\title{
BMJ Open Chronic fatigue syndrome (CFS) or myalgic encephalomyelitis (ME) is different in children compared to in adults: a study of UK and Dutch clinical cohorts
}

\author{
Simon M Collin, ${ }^{1}$ Roberto Nuevo, ${ }^{1}$ Elise M van de Putte, ${ }^{2}$ Sanne L Nijhof, ${ }^{2}$ \\ Esther Crawley ${ }^{1}$
}

To cite: Collin SM, Nuevo R, van de Putte EM, et al. Chronic fatigue syndrome (CFS) or myalgic encephalomyelitis (ME) is different in children compared to in adults: a study of UK and Dutch clinical cohorts. BMJ Open 2015;5: 008830.

doi:10.1136/bmjopen-2015008830

- Prepublication history and additional material is available. To view please visit the journal (http://dx.doi.org/ 10.1136/bmjopen-2015008830)

Received 19 May 2015 Accepted 24 July 2015

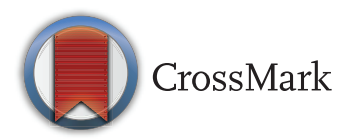

${ }^{1}$ Centre for Child \& Adolescent Health, School of Social and Community Medicine, University of Bristol, Bristol, UK

${ }^{2}$ Department of Paediatrics, Wilhelmina Children's Hospital, University Medical Centre, Utrecht,

The Netherlands

Correspondence to Dr Esther Crawley; esther.crawley@bristol.ac.uk

\section{ABSTRACT}

Objective: To investigate differences between young children, adolescents and adults with chronic fatigue syndrome/myalgic encephalomyelitis (CFS/ME).

Study design: Comparison of clinical cohorts from 8 paediatric and 27 adult CFS/ME services in the UK and a paediatric randomised controlled trial from the Netherlands. Outcome measures include: fatigue (the UK-Chalder Fatigue Scale); Disability (the UK-SF-36 physical function subscale; the Netherlands- $\mathrm{CHQ}$ CF87); school attendance, pain, anxiety and depression (the UK-Hospital Anxiety \& Depression Scale, Spence Children's Anxiety Scale; the Netherlands-Spielberger State-Trait Anxiety Inventory for Children, Children's Depression Inventory); symptoms; time-to-assessment; and body mass index. We used multinomial regression to compare younger (aged $<12$ years) and older (aged 12-18 years) children with adults, and logistic regression to compare UK and Dutch adolescents.

Results: Younger children had a more equal gender balance compared to adolescents and adults. Adults had more disability and fatigue, and had been ill for longer. Younger children were less likely to have cognitive symptoms (OR 0.18 ( $95 \% \mathrm{Cl} 0.13$ to 0.25$)$ ) and more likely to present with a sore throat (OR 1.42 (1.07 to 1.90). Adolescents were more likely to have headaches (81.1\%, OR $1.56(1.36 \%$ to $1.80 \%))$ and less likely to have tender lymph nodes, palpitations, dizziness, general malaise and pain, compared to adults. Adolescents were more likely to have comorbid depression (OR 1.51 (1.33 to 1.72)) and less likely to have anxiety (OR 0.46 (0.41 to 0.53$)$ ) compared to adults.

Conclusions: Paediatricians need to recognise that children with CFS/ME present differently from adults. Whether these differences reflect an underlying aetiopathology requires further investigation.

Trial registration numbers: FITNET trial registration numbers are ISRCTN59878666 and NCT00893438. This paper includes secondary (post-results) analysis of data from this trial, but are unrelated to trial outcomes.

\section{Strengths and limitations of this study}

- This study benefited from large sample sizes, and data on chronic fatigue syndrome/myalgic encephalomyelitis (CFS/ME) symptoms and comorbid mood disorders were collected in the same way from UK children and adults.

- Adults and children were recruited from specialist CFS/ME services in the UK and the Netherlands, so the results may not be generalisable to other settings, such as primary care.

- Fatigue, disability, pain and mood, were measured differently in the UK and the Netherlands, making it difficult to compare these characteristics directly.

\section{INTRODUCTION}

The incidence of chronic fatigue syndrome/ myalgic encephalomyelitis (CFS/ME) has two distinct age peaks, at 10-19 years and 30-39 years. ${ }^{1}$ Little is known about the underlying aetiopathology of CFS/ME and whether it differs between children and adults. Studies investigating heterogeneity (phenotypes) in adult ${ }^{2-5}$ and paediatric ${ }^{6}$ CFS/ME patients have described some similarities in the delineation of paediatric and adult CFS/ME phenotypes, based mainly on the presence/absence of musculoskeletal pain and 'acute' illness symptoms (swollen glands, sore throat, headache). However, prognosis is much better in children than in adults, with $54-94 \%$ of children improving or making a complete recovery from the illness, ${ }^{7}{ }^{8}$ compared with a recovery rate of not more than $22 \%$ in adults. ${ }^{9}$

No previous study has compared the clinical features of paediatric and adult CFS/ME patients, which means that clinical guidelines, teaching and definitions for paediatric 
patients are based on adult descriptions of CFS/ME. Paediatricians also need more information about age-related differences between younger and older (adolescent) children. We previously compared 32 primary school-aged children with adolescents, which showed that they had similar symptoms at presentation. ${ }^{10}$ However, the sample size was too small to allow detailed comparison between the two age groups.

In this study, we used three large clinical cohorts to compare the characteristics of CFS/ME in children, adolescents and adults. We hypothesised that CFS/ME in adults would present differently in children compared to adults, but that younger children would be similar to older children. We also compared adolescent patients diagnosed with CFS/ME in the UK with adolescent patients recruited into a large randomised controlled CFS/ME treatment trial in the Netherlands, ${ }^{8}$ to investigate whether paediatric CFS/ME phenotypes might be robust across different countries and healthcare settings, as has been demonstrated for adult patients with CFS/ME. ${ }^{11}$

\section{METHODS}

\section{UK adult and paediatric clinical cohorts}

UK data were collected from all NHS specialist services (see online supplementary material) that participated in the CFS/ME National Outcomes Database between August 2004 and October 2014. During this period, clinical assessment data and patient-reported measures were collected for approximately 10000 adults and 1500 children and young people, from 27 adult and 8 paediatric $\mathrm{CFS} / \mathrm{ME}$ services. Patients were included if they were given a diagnosis of $\mathrm{CFS} / \mathrm{ME}$ in accordance with Centers for Disease Control and Prevention (CDC) criteria (to 2007) ${ }^{12} 13$ or National Institute for Health and Care Excellence (NICE) guidance (from 2007 onwards). ${ }^{14}$ These criteria are broadly similar, however, CDC criteria specify symptom duration of 6 months compared with 4 months in the NICE guidelines. CDC criteria also require that patients present with at least four of eight named symptoms (subjective memory impairment, sore throat, tender lymph nodes, muscle pain, joint pain, headaches, unrefreshing sleep and postexertional malaise), whereas NICE criteria include these symptoms (plus flu-like symptoms, dizziness, nausea and palpitations) for guidance only.

\section{Netherlands paediatric clinical cohort}

Children were recruited from paediatricians throughout the Netherlands for the FITNET trial for adolescents with CFS/ME, between January 2008 and February $2010{ }^{8}$ Children were included in the trial if they were aged 12-18 years, had a primary diagnosis of CFS/ME in accordance with CDC criteria, had severe fatigue (Checklist Individual Strength (CIS20-R) ${ }^{15}$ subjective fatigue subscale score $>40$ ) and were physically disabled (Child Health Questionnaire (CHQ-CF87) ${ }^{16}$ physical function subscale score $\leq 85$ or school attendance $\leq 85 \%)$. Children were assessed by a paediatrician and had screening blood tests to exclude other causes of fatigue.

\section{Ethical approvals}

UK cohorts

The North Somerset and South Bristol Research Ethics Committee decided that collection and analysis of CFS/ ME patient data constituted service evaluation and did not require ethical review by a NHS Research Ethics Committee or approval by NHS Research and Development offices (REC reference number 07/ Q2006/48).

\section{Dutch cohort}

The FITNET study reviewed and approved by the Medical Ethical Committee of the University Medical Centre Utrecht (reference 07/196-K) and the Medical Ethical Committee of the Radboud University Nijmegen Medical Centre (reference AMO number 07/105). Patients and their parents will receive verbal and written information about the study and informed consent will be obtained before randomisation. Trial registration: ISRCTN59878666 and (ClinicalTrials.gov) NCT00893438.

\section{Clinical and patient-reported measures}

Symptoms and comorbidities

In the UK and in the Netherlands, clinicians prospectively collected symptoms used to make a diagnosis of CFS/ME (cognitive dysfunction, sleep disturbance/unrefreshing sleep, postexertional malaise, joint pain, muscle pain, headaches, painful lymph nodes, sore throat, general malaise/flu-like symptoms, dizziness, nausea and palpitations).${ }^{14}{ }^{13}$ In the UK, adult and paediatric services also prospectively asked patients whether they had received a diagnosis of depression or anxiety, migraine, irritable bowel syndrome, Fibromyalgia or Chronic Regional Pain Disorder. Time to assessment was calculated as the time from reported symptom onset to assessment in the CFS/ME specialist clinic.

\section{Fatigue}

In the UK, fatigue was measured using the Chalder fatigue scale (range 0-33) ${ }^{17}$ Internal consistency for this instrument, calculated by Cronbach's $\alpha$, ranges from 0.88 to $0.90 .^{18}$ In the Netherlands, fatigue was measured using the 'subjective fatigue' subscale of the CIS20-R (range 8-56). This questionnaire has good reliability, discriminative validity and internal consistency (Cronbach's $\alpha=0.93) .{ }^{19}$

\section{Disability}

In the UK, disability was measured using the 10-item physical function subscale of the Short form 36 (SF-36). ${ }^{20}$ Children scored between 0 ('yes, limited a lot') and 10 ('no, not limited at all') for each item, so 
that children with the worst physical function scored 0 while those with good physical function scored 100. In the Netherlands, physical disability was measured with the physical functioning subscale of the CHQ-CF87. ${ }^{16}$ This is scored $0-100 \%$ with a lower score indicating more disability. This assessment tool is reliable and has been validated with a good internal consistency (Cronbach's $\alpha=0.86) .^{21}$

\section{School attendance}

School attendance was measured in the UK by asking how the young person would describe their attendance as a percentage of expected attendance: 'None', 'About $10 \%$ (eg, one half day)', 'About 20\% (eg, one day)', 'About $40 \%$ (eg, two days)', 'About 60\% (eg, three days)', 'About $80 \%$ (eg, four days)' and 'Full time $(100 \%)$ '. In the Netherlands, school attendance was selfrecorded daily for 12 days prior to assessment and averaged. These data were shown to be consistent with school records. ${ }^{8}$

\section{Pain}

In the UK, a visual analogue pain rating scale was used to measure pain prior to assessment, with a score of 0 for 'no pain' and 100 for 'pain as bad as possible'. Pain was categorised as: none (0-4); mild (5-44), moderate (45-74), severe (75-100). In the FITNET trial, participants recorded their pain level using a Likert scale $(0-4)$ at four separate times each day for 12 days prior to assessment. ${ }^{22}$

\section{Mood}

In the UK, the Hospital and Anxiety Depression Scale $(\text { HADS })^{23}$ was used to assess mood in children aged 12 years and older. The HADS is a 14-item inventory with anxiety and depression subscales. ${ }^{24}$ Cut-off scores for HADS depression were $>9$ for boys, $>10$ for girls ${ }^{25}$ and $>12$ for adults. ${ }^{26}$ Likewise, the cut-off for identifying clinical presentations of anxiety symptoms was $>12$ for boys, $>16$ for girls, ${ }^{25}>11$ for men and $>12$ for women. ${ }^{26}$ In the Netherlands, anxiety was assessed using the Spielberger State-Trait Anxiety Inventory for Children (STAIC), ${ }^{27}$ comprising 20 questions, each on a 3-point scale. Depression was measured using a Dutch translation of the 27-item Children's Depression Inventory (CDI). ${ }^{28}$ This instrument has a high degree of internal consistency, with Cronbach's $\alpha$ ranging from 0.71 to $0.89 .^{29}$ Cut-off scores for depression and anxiety were CDI score $>15$ and STAIC score $>43 .^{8}$

\section{Statistical analyses}

We performed descriptive analyses separately for each of the four groups: UK children aged $<12$ years, UK adolescents aged 12-18 years, Dutch adolescents aged 1218 years and UK adults (aged 19-65 years). We used linear regression to estimate differences in disability and fatigue between UK paediatric and adult patients. We used multinomial logistic regression analyses to compare child and adolescent with adult (reference category) groups, controlling for gender. Binary logistic regression analyses were used to test for differences between adolescents from the UK and the Netherlands. Inventories were coded as missing if $>1$ question was missing. On the HADS, each seven-item subscale was excluded if there was more than one question missing. Questions for which two answers were given were coded as missing. Total scores were corrected for the number of missing items. Stata (StataCorp 2013, Stata Statistical Software: Release 13, College Station, Texas, USA: StataCorp LP) was used for all analyses.

\section{RESULTS}

The UK paediatric cohort comprised 1568 UK adolescents aged $12-18$ years and 210 children aged $<12$ years. Data on comorbid disorders were collected from 2010, and these data were available for approximately 900 children and adolescents (exact numbers shown in table 1). Body mass index (BMI) data were available for $37 \%$ $(579 / 1568)$ of the adolescents and $24 \%(49 / 204)$ of the younger children. The UK adult cohort comprised 10675 patients. Symptom data were collected from adults since 2010, and these data were available for approximately 7000 adults (exact numbers shown in table 1). The Dutch adolescent group had almost complete data, with missing data on BMI in only one patient.

Table 2 shows that younger children $(<12$ years old) had a more equal gender balance $(56.7 \%$ female $)$ compared to adolescents $(74.1 \%$ and $82.2 \%$ in the UK and the Netherlands, respectively) and adults (77.9\%). BMI was similar in younger children and UK and Dutch adolescents. Duration of illness prior to assessment was longest in adults (median 36 months), compared to 16 months in UK adolescents and 12 months in UK primary school-aged children. Disability and fatigue were similar in younger and older UK children, but adults had lower mean physical function than adolescents ( -8.2 points (95\% CI -9.7 to -6.7 points) on SF-36 physical function subscale) and higher mean fatigue (2.1 points (1.8-2.4 points) on the Chalder Fatigue Scale. Adjustment for duration of illness did not change the difference in fatigue, but did slightly attenuate the difference in physical function $(-6.7$ points $(-8.2$ to -5.2 points)). Mean disability scores were not directly comparable between UK and Dutch adolescents because these had been obtained using different instruments.

\section{Symptoms and comorbidities in young children, adolescents and adults (UK cohorts)}

Table 1 shows that children under 12 (76.5\%; OR 0.18 (95\% CI 0.13 to 0.25$)$ ) are less likely to describe cognitive symptoms at assessment compared to adults (95.3\%) and adolescents $(86.7 \%)$. They are also less likely to have problems with sleeping $(85.1 \%$ vs $96.4 \%$; OR 0.23 (0.15, $0.34)$ ). They are more likely to present with sore throats (62.3\%; OR $1.42(1.07 \%$ to $1.90 \%))$ compared to adults 
Table 1 Differences in the presence of symptoms among UK children, adolescents and adults with CFS/ME, showing ORs derived from multinomial logistic regression controlling for gender (adults as reference group unless otherwise indicated)

\begin{tabular}{|c|c|c|c|c|c|}
\hline \multirow[b]{2}{*}{ Symptoms } & \multicolumn{2}{|c|}{$\begin{array}{l}\text { Younger children } \\
\text { (aged <12 years) }\end{array}$} & \multicolumn{2}{|c|}{ Adolescents (aged 12-18 years) } & \multirow{2}{*}{$\begin{array}{l}\text { Adults (aged } \\
19-65 \text { years) } \\
\text { N/total (\%) }\end{array}$} \\
\hline & N/total (\%) & OR (95\% Cl) & N/total (\%) & OR $(95 \% \mathrm{Cl})$ & \\
\hline Cognitive dysfunction & $156 / 204(76.5)$ & $0.18(0.13$ to 0.25$)$ & $1281 / 1478(86.7)$ & $0.34(0.28$ to 0.40$)$ & $6586 / 6921$ (95.2) \\
\hline Sore throat & $127 / 204(62.3)$ & $1.42(1.07$ to 1.90$)$ & $860 / 1482(58.0)$ & $1.10(0.98$ to 1.24$)$ & $3834 / 6823(56.1)$ \\
\hline Tender lymph nodes & 95/203 (46.8) & $1.02(0.77$ to 1.36$)$ & $601 / 1469$ (40.9) & 0.74 (0.66 to 0.83$)$ & $3314 / 6785$ (48.8) \\
\hline Muscle pain & $154 / 204(75.5)$ & 0.45 (0.32 to 0.63$)$ & 1093/1484 (73.7) & 0.38 (0.33 to 0.43$)$ & $6133 / 6944$ (88.3) \\
\hline Joint pain & $116 / 205(56.6)$ & 0.43 (0.32 to 0.57$)$ & $895 / 1483(60.4)$ & 0.47 (0.42 to 0.53$)$ & $5276 / 6878(76.7)$ \\
\hline Headaches & $152 / 204(74.5)$ & $1.14(0.83$ to 1.57$)$ & $1206 / 1487(81.1)$ & $1.56(1.36$ to 1.80$)$ & $5063 / 6870$ (73.7) \\
\hline Sleep dysfunction & $171 / 201(85.1)$ & $0.23(0.15$ to 0.34$)$ & $1394 / 1462(95.4)$ & 0.77 (0.59 to 1.02$)$ & $6678 / 6926(96.4)$ \\
\hline Postexertional malaise & 196/205 (95.6) & $0.50(0.25$ to 0.99$)$ & $1444 / 1485$ (97.2) & 0.75 (0.53 to 1.07$)$ & $6748 / 6890$ (97.9) \\
\hline Nausea & $87 / 205(42.4)$ & 0.59 (0.44 to 0.78$)$ & $581 / 1478(39.3)$ & 0.56 (0.50 to 0.63$)$ & $3602 / 6796(53.0)$ \\
\hline Palpitations & $32 / 113(28.3)$ & 0.71 (0.47 to 1.08$)$ & $329 / 985$ (33.4) & 0.85 (0.73 to 0.97$)$ & 2533/6771 (37.4) \\
\hline Dizziness & 86/201 (42.8) & 1.05 (0.79 to 1.39$)$ & 451/1479 (30.5) & 0.65 (0.57 to 0.73 ) & $2735 / 6816(40.1)$ \\
\hline $\begin{array}{l}\text { General malaise/flu-like } \\
\text { symptoms }\end{array}$ & $77 / 116(66.4)$ & 0.69 (0.47 to 1.02$)$ & $661 / 987(67.0)$ & 0.68 (0.59 to 0.78$)$ & $5131 / 6835(75.1)$ \\
\hline \multicolumn{6}{|l|}{ Pain } \\
\hline No pain (ref cat) & $18 / 180(10.0)$ & - & $166 / 1349$ (12.3) & - & $635 / 8779$ (7.2) \\
\hline Mild pain & $51 / 180(28.3)$ & $0.69(0.40$ to 1.19$)$ & $370 / 1349(27.4)$ & 0.52 (0.43 to 0.64$)$ & $2731 / 8779(31.1)$ \\
\hline Moderate pain & $73 / 180(40.6)$ & 0.84 (0.49 to 1.41$)$ & $538 / 1349$ (39.9) & 0.61 (0.50 to 0.74$)$ & $3436 / 8779$ (39.1) \\
\hline Severe pain & $38 / 180(21.1)$ & 0.76 (0.43 to 1.35$)$ & $275 / 1349(20.4)$ & 0.54 (0.44 to 0.67$)$ & $1977 / 8779(22.5)$ \\
\hline $\begin{array}{l}\text { Depression symptoms } \\
\text { (HADS) }\end{array}$ & - & - & $379 / 1360(27.9)$ & 1.51 (1.33 to 1.72$)$ & $1916 / 9420(20.3)$ \\
\hline $\begin{array}{l}\text { Anxiety symptoms } \\
\text { (HADS) }\end{array}$ & - & - & 285/1357 (21.0) & $0.46(0.41$ to 0.53$)$ & $3420 / 9393(36.4)$ \\
\hline $\begin{array}{l}\text { Anxiety symptoms } \\
\text { (SCAS) }^{*}\end{array}$ & $56 / 173(11.3)$ & 1.09 (0.75 to 1.58$)$ & $440 / 759(58.0)$ & - & - \\
\hline \multicolumn{6}{|l|}{ Comorbid disorders } \\
\hline Depressive disorder & $0 / 10(0.0)$ & - & $61 / 785(7.8)$ & $0.17(0.13$ to 0.23$)$ & $2195 / 4488(32.8)$ \\
\hline Anxiety disorder & 9/99 (9.1) & $0.19(0.10$ to 0.38$)$ & $128 / 782(16.4)$ & 0.37 (0.30 to 0.45$)$ & $2328 / 6655$ (35.0) \\
\hline Migraine & $5 / 106(4.7)$ & 0.19 (0.08 to 0.46$)$ & $126 / 818(15.4)$ & 0.63 (0.52 to 0.77 ) & $1533 / 6747(22.7)$ \\
\hline $\begin{array}{l}\text { Irritable bowel } \\
\text { syndrome }\end{array}$ & $8 / 106(7.6)$ & $0.17(0.08$ to 0.35$)$ & $67 / 807(8.3)$ & $0.18(0.14$ to 0.23$)$ & $2312 / 6749$ (34.3) \\
\hline Fibromyalgia & 2/105 (1.9) & 0.05 (0.01 to 0.21$)$ & 23/813 (2.8) & 0.07 (0.05 to 0.11$)$ & 1919/6707 (28.6) \\
\hline $\begin{array}{l}\text { Regional pain } \\
\text { syndrome }\end{array}$ & $2 / 105(1.9)$ & $0.50(0.12$ to 2.03$)$ & $12 / 808(1.5)$ & 0.37 (0.21 to 0.67$)$ & $261 / 6667$ (3.9) \\
\hline
\end{tabular}

*Reference group: children aged $12-18$ years.

CFS/ME, chronic fatigue syndrome/myalgic encephalomyelitis; HADS, Hospital and Anxiety Depression Scale; SCAS, Spence Children's Anxiety Scale.

(56.1\%). The symptom of postexertional malaise is slightly less common in those under $12(95.6 \%$; OR 0.50 $(0.25 \%$ to $0.99 \%))$ than in adults $(97.9 \%)$.

Adolescents are more likely to present with headaches (81.1\%; OR $1.56(1.36 \%$ to $1.80 \%))$ compared to younger children (74.5\%) and adults (73.7\%). Adolescents were less likely to describe cognitive symptoms $(86.7 \%$; OR $=0.34(0.28 \%$ to $0.40 \%))$ compared to adults $(95.2 \%)$. Tender lymph nodes, palpitations, dizziness and general malaise, and either mild, moderate or severe pain (compared to 'no pain'), were less likely in teenagers than in adults.

We compared symptoms between younger children and adolescents. Although younger children were less likely to present with cognitive dysfunction (OR 0.53 (0.37 to 0.76$)$ ), problems with sleep (OR 0.29 (0.19 to $0.47)$ ), or headaches (OR 0.73 (0.52 to 1.03$)$ ), they were more likely to present with recurrent frequent sore throats (OR 1.29 (0.95 to 1.75$)$ ), tender lymph nodes (OR 1.38 (1.03 to 1.86)) and dizziness (OR 1.62 (1.20 to 2.20)).

Adolescents were more likely to score above the HADS threshold for depression (27.9\% vs $20.3 \%$, OR 1.51 (1.33 to 1.72)), but below the threshold for anxiety (21\%, OR 0.46 (0.41 to 0.53)), compared to adults $(36.2 \%)$. However, previous diagnoses of depression and anxiety (recorded as comorbid by the clinician at time of assessment) were much less common in children and adolescents compared to adults, as were all of the other comorbidities (migraine, irritable bowel syndrome, fibromyalgia and regional pain syndrome).

\section{Comparison between adolescents in the UK and the} Netherlands

Table 3 shows that teenagers (aged 12-18 years) with CFS/ME tended to present with similar symptoms in the 
Table 2 Characteristics of UK children, adolescents and adults, and Dutch adolescents

\begin{tabular}{|c|c|c|c|c|c|c|c|c|}
\hline \multirow[b]{2}{*}{ Characteristics } & \multicolumn{2}{|c|}{$\begin{array}{l}\text { UK (aged } \\
<12 \text { years) }\end{array}$} & \multicolumn{2}{|c|}{$\begin{array}{l}\text { UK (aged } \\
12-18 \text { years) }\end{array}$} & \multicolumn{2}{|c|}{$\begin{array}{l}\text { NL (aged } \\
12-18 \text { years) }\end{array}$} & \multicolumn{2}{|c|}{$\begin{array}{l}\text { UK adults (aged } \\
19-65 \text { years) }\end{array}$} \\
\hline & $\mathbf{N}$ & & $\mathbf{N}$ & & $\mathbf{N}$ & & $\mathbf{N}$ & \\
\hline Age (years), mean (SD) & 210 & $9.3(2.0)$ & 1568 & $15.0(1.8)$ & 135 & $15.8(1.3)$ & 10675 & $40.1(11.7)$ \\
\hline Sex (female), frequency (\%) & 210 & $119(56.7)$ & 1568 & $1162(74.1)$ & 135 & $111(82.2)$ & 10675 & $8(77.9)$ \\
\hline BMI $\left(\mathrm{kg} / \mathrm{m}^{2}\right)$, mean $(\mathrm{SD})$ & 49 & $18.5(3.8)$ & 579 & $22.1(6.5)$ & 134 & $21.0(2.9)$ & 5598 & $26.2(5.7)$ \\
\hline Duration of illness (months), median & 161 & & 1293 & & 135 & & 8488 & \\
\hline Disab & 178 & $45,25-65$ & 1411 & $33-70$ & 135 & $52,48-55$ & 9282 & \\
\hline Fatiguet (Chalder), median (IQR) & 190 & $23,20-28$ & 1425 & $25,22-29$ & - & _ & 9405 & $28,24-3$ \\
\hline
\end{tabular}

*UK cohorts used SF-36 physical function subscale to measure disability. The Dutch cohort used the CHQ-CF87 physical function subscale.

†All Dutch children had severe fatigue (CIS20-R subjective fatigue scale score $\geq 40$ ).

BMI, body mass index; CHQ-CF87, Child Health Questionnaire; SF-36, short form 36.

UK and the Netherlands, but postexertional malaise ( $97.2 \%$ vs $86.7 \%$; OR 5.81 (3.21 to 10.51$)$ ), severe pain (20.4\% vs $9 \%$; OR 3.12 (1.49 to 6.54$)$ ), depression (27.9\% vs $17 \%$; OR 2.01 (1.26 to 3.22$)$ and anxiety ( $21 \%$ vs $11.1 \%$; OR 2.62 (1.49 to 4.59$)$ ), were more common in UK adolescents, and headaches $(81.1 \%$ vs $89.6 \%$; OR 0.54 (0.30 to 0.96$)$ ) were less common.

\section{DISCUSSION}

This is the first study to show that children with CFS/ME present differently compared to adults with CFS/ME. Children and adolescents had less fatigue and better physical function, and were much less likely to have been given a diagnosis of comorbid illnesses, including depression and anxiety. Younger children were more likely to present with sore throat and were less likely to have sleep or memory problems, often considered cardinal symptoms in adults. Adolescents were more likely to present with cognitive and sleep dysfunction than were younger children, but less likely to present with tender lymph nodes and dizziness. Despite differences in sampling, UK adolescents with CFS/ME were similar to teenagers in the Netherlands, suggesting that the symptomatology of paediatric CFS/ME is generalisable to other populations and is robust across different healthcare settings.

The main strengths of this study were the large sample sizes, and the fact that symptoms and comorbid mood disorders were collected in the same way in UK children and adults. Adults and children were recruited from specialist CFS/ME services in the UK and the Netherlands, so the results may not be generalisable to other settings, such as primary care. Fatigue, disability, pain and mood

Table 3 Differences in the presence of symptoms among UK and Dutch adolescents with CFS/ME, showing OR derived from logistic regression controlling for age and sex (Dutch adolescents as reference group)

\begin{tabular}{|c|c|c|c|c|c|}
\hline & $\mathbf{N}$ & $\begin{array}{l}\text { UK } \\
\text { Frequency (\%) }\end{array}$ & $\mathbf{N}$ & $\begin{array}{l}\text { Netherlands } \\
\text { Frequency (\%) }\end{array}$ & OR $(95 \% \mathrm{Cl})^{\star}$ \\
\hline Cognitive dysfunction & 1478 & $1281(86.7)$ & 135 & $123(91.1)$ & 0.77 (0.41 to 1.43$)$ \\
\hline Sore throat & 1482 & $860(58.0)$ & 135 & 78 (57.8) & 1.03 (0.72 to 1.48$)$ \\
\hline Tender lymph nodes & 1469 & 601 (40.9) & 135 & 49 (36.3) & 1.28 (0.88 to 1.85$)$ \\
\hline Muscle pain & 1484 & 1093 (73.7) & 135 & $103(76.3)$ & 0.93 (0.61 to 1.41$)$ \\
\hline Joint pain & 1483 & 895 (60.4) & 135 & $87(64.4)$ & 0.86 (0.59 to 1.24$)$ \\
\hline Headaches & 1487 & $1206(81.1)$ & 135 & $121(89.6)$ & 0.54 (0.30 to 0.96$)$ \\
\hline Sleep dysfunction & 1462 & 1394 (95.4) & 135 & $129(95.6)$ & 1.02 (0.43 to 2.42$)$ \\
\hline Postexertional malaise & 1485 & $1444(97.2)$ & 135 & $117(86.7)$ & 5.66 (3.07 to 10.45 \\
\hline Pain (ref no pain)† & 1349 & 166 (12.3) & 134 & $22(16.4)$ & - \\
\hline Mild pain & 1349 & 370 (27.4) & 134 & $56(41.8)$ & 0.98 (0.57 to 1.67$)$ \\
\hline Moderate pain & 1349 & 538 (39.9) & 134 & $44(32.8)$ & 1.81 (1.04 to 3.13 ) \\
\hline Severe pain & 1349 & 275 (20.4) & 134 & $12(9.0)$ & 3.12 (1.49 to 6.54$)$ \\
\hline Depression‡ & 1360 & 379 (27.9) & 135 & $23(17.0)$ & 2.01 (1.26 to 3.22 ) \\
\hline Anxiety§ & 1357 & $285(21.0)$ & 135 & $15(11.1)$ & 2.62 (1.49 to 4.59$)$ \\
\hline
\end{tabular}

${ }^{*}$ Adjusted for age and sex.

†Pain in UK adolescents was measured on a visual analogue scale, categorised as none (0-4), mild (5-44), moderate (45-74) and severe (75-100); pain in Dutch adolescents was measured on a 0-4 Likert scale at four separate times each day for 12 days.

fDepression in UK adolescents was defined as HADS depression score $>9$ (boys) or $>10$ (girls); depression in Dutch adolescents was defined as CDI score $>15$.

$\S$ Anxiety in UK adolescents was defined as HADS anxiety score $>12$ (boys) or $>16$ (girls); anxiety in Dutch adolescents was defined as STAIC score $>43$.

CDI, Children's Depression Inventory; CFS/ME, chronic fatigue syndrome/myalgic encephalomyelitis; HADS, Hospital and Anxiety Depression Scale; STAIC, Spielberger State-Trait Anxiety Inventory for Children. 
were measured differently in the UK and the Netherlands, making it difficult to directly compare these characteristics. Also, while there is evidence for the validity and reliability of these instruments for adults diagnosed with $\mathrm{CFS} / \mathrm{ME},{ }^{30}$ their use among paediatric CFS/ME patients has not been thoroughly evaluated, ${ }^{31}$ and we cannot assume that scores for adults, adolescents and children are comparable.

Data for UK adolescents were collected routinely as this group attended specialist CFS/ME services, whereas data for Dutch adolescents were obtained from a clinical trial. In the Dutch cohort, CFS/ME was diagnosed or confirmed in a tertiary academic hospital setting. However, since referrals were obtained nationwide from various sources (general practitioners as well as paediatricians), we consider that our study population was representative of the Dutch paediatric CFS/ME population.

The differences in symptom presentation that we found between younger and older children were not found in our previous comparison of these age groups, ${ }^{10}$ probably because this earlier study was insufficiently powered to detect such differences. It is striking that the gender balance is more equal in younger children $(57 \%$ female), compared to adolescents $(74.1 \%)$ and adults $(77.9 \%)$. This shift in gender balance is consistent with population data, where an equal gender balance ( $49.6 \%$ female) has been described in a population cohort at age 13 years. ${ }^{32}$ Studies recruiting teenagers from secondary schools have consistently shown a female-to-male ratio of approximately $3: 1,{ }^{33} 34$ suggesting that, during adolescence, the prevalence of CFS/ME increases in females but not in males. ${ }^{35}$

Adolescents from the UK and the Netherlands presented with similar symptoms, although headaches were less common, and postexertional malaise, severe pain and mood disorders were more common in UK patients. The difference in postexertional malaise could be explained by the fact that this is considered a cardinal symptom in the UK. The lower prevalence of anxiety and depression in the Dutch cohort could be because high scores for mood disorder were a reason for further psychological assessment to exclude primary mood disorders, leading to possible exclusion from the study. Also, the UK and Dutch cohorts used different instruments to measure mood (and pain), and this is likely to contribute to discrepancies when these measures are categorised to indicate presence/absence (or degree) of symptoms.

Paediatricians need to be aware that children with CFS/ME present differently from adults with CFS/ME. Younger children are more likely to present with recurrent sore throats and teenagers are likely to present with headaches. Further research should investigate whether these differences in presentation reflect the underlying aetiopathology or explain prognostic differences.

Contributors This study was conceived by EC. SMC and RN collated and analysed the data. SMC wrote the first draft of the manuscript. EvdP, SN and EC provided clinical input and interpretation. All the authors contributed to revisions, and approved the final version of the manuscript.
Funding SMC was funded by an NIHR Postdoctoral Fellowship (PDF-2013-06-011); RN was funded by an MRC research grant (MR/ K020269/1); EC was funded by an NIHR Senior Research Fellowship (SRF-2013-06-013). This article/paper/report presents independent research funded by the NIHR. The views expressed are those of the authors and not necessarily those of the NHS, the NIHR or the Department of Health. The funders had no role in the design, conduct, writing-up or submission of this manuscript.

Competing interests None declared.

Patient consent Obtained.

Ethics approval North Somerset and South Bristol NHS Research Ethics Committee (REC reference number 07/Q2006/48); Medical Ethical Committee of the University Medical Centre Utrecht (reference 07/196-K) and the Medical Ethical Committee of the Radboud University Nijmegen Medical Centre (reference AMO number 07/105).

Provenance and peer review Not commissioned; externally peer reviewed.

Data sharing statement Original data may be made available to bona fide researchers from academic institutions, subject to the original terms of ethical review for each study: contact EC for UK cohort data, and SN for NL cohort data.

Open Access This is an Open Access article distributed in accordance with the terms of the Creative Commons Attribution (CC BY 4.0) license, which permits others to distribute, remix, adapt and build upon this work, for commercial use, provided the original work is properly cited. See: http:// creativecommons.org/licenses/by/4.0/

\section{REFERENCES}

1. Bakken I, Tveito K, Gunnes N, et al. Two age peaks in the incidence of chronic fatigue syndrome/myalgic encephalomyelitis: a populationbased registry study from Norway 2008-2012. BMC Med 2014; 12:167.

2. Carmel L, Efroni S, White PD, et al. Gene expression profile of empirically delineated classes of unexplained chronic fatigue. Pharmacogenomics 2006;7:375-86.

3. Cella M, Chalder T, White PD. Does the heterogeneity of chronic fatigue syndrome moderate the response to cognitive behaviour therapy? An exploratory study. Psychother Psychosom 2011;80:353-8.

4. Sullivan PF, Smith W, Buchwald D. Latent class analysis of symptoms associated with chronic fatigue syndrome and fibromyalgia. Psychol Med 2002;32:881-8.

5. Janal MN, Ciccone DS, Natelson BH. Sub-typing CFS patients on the basis of 'minor' symptoms. Biol Psychol 2006;73:124-31.

6. May M, Emond A, Crawley E. Phenotypes of chronic fatigue syndrome in children and young people. Arch Dis Child 2010;95:245-9.

7. Joyce J, Hotopf M, Wessely S. The prognosis of chronic fatigue and chronic fatigue syndrome: a systematic review. QJM 1997;90:223-33.

8. Nijhof SL, Bleijenberg G, Uiterwaal CS, et al. Effectiveness of internet-based cognitive behavioural treatment for adolescents with chronic fatigue syndrome (FITNET): a randomised controlled trial. Lancet 2012;379:1412-18.

9. White $\mathrm{P}$, Goldsmith $\mathrm{K}$, Johnson $\mathrm{A}$, et al. Comparison of adaptive pacing therapy, cognitive behaviour therapy, graded exercise therapy, and specialist medical care for chronic fatigue syndrome (PACE): a randomised trial. Lancet 2011;377:823-36.

10. Davies SM, Crawley E. Chronic fatigue syndrome in children aged 11 years old and younger. Arch Dis Child 2008;93:419-21.

11. Hickie I, Davenport T, Vernon SD, et al. Are chronic fatigue and chronic fatigue syndrome valid clinical entities across countries and health-care settings? Aust NZ J Psychiatry 2009;43:25-35.

12. Reeves WC, Lloyd A, Vernon SD, et al. Identification of ambiguities in the 1994 chronic fatigue syndrome research case definition and recommendations for resolution. BMC Health Serv Res 2003;3:25.

13. Fukuda K, Straus SE, Hickie I, et al. The chronic fatigue syndrome: a comprehensive approach to its definition and study. International Chronic Fatigue Syndrome Study Group. Ann Intern Med 1994;121:953-9.

14. National Institute for Health and Care Excellence (NICE). Chronic fatigue syndrome/myalgic encephalomyelitis (or encephalopathy): 
Diagnosis and management of CFS/ME in adults and children (NICE guidelines CG53). London: NICE, 2007.

15. Vercoulen JH, Swanink CM, Fennis JF, et al. Dimensional assessment of chronic fatigue syndrome. J Psychosom Res 1994;38:383-92.

16. Landgraf JM Abetz L, Ware JE. The CHQ user's manual. Boston, MA: Health Act, 1999.

17. Chalder T, Berelowitz G, Pawlikowska T, et al. Development of a fatigue scale. J Psychosom Res 1993;37:147-53.

18. Cella M, Chalder T. Measuring fatigue in clinical and community settings. J Psychosom Res 2010;69:17-22.

19. Vercoulen JHMM, Swanink CMA, Fennis JFM, et al. Dimensional Assessment of Chronic Fatigue Syndrome. J Psychosom Res 1994;38:383-92.

20. Ware JE, Sherbourne CD. The MOS 36-item short-form health survey (SF-36). I. Conceptual framework and item selection. Med Care 1992;30:473-83.

21. Raat $\mathrm{H}$, Landgraf JM, Bonsel GJ, et al. Reliability and validity of the child health questionnaire-child form (CHQ-CF87) in a Dutch adolescent population. Qual Life Res 2002:11:575-81.

22. Nijhof SL, Priesterbach LP, Bleijenberg G, et al. Functional improvement is accompanied by reduced pain in adolescent chronic fatigue syndrome. Pain Med 2013;14:1435-8.

23. Zigmond AS, Snaith RP. The hospital anxiety and depression scale. Acta Psych Scand 1983;67:361-70.

24. Crawford JR, Henry JD, Crombie C, et al. Normative data for the HADS from a large non-clinical sample. Br J Clin Psychol 2001;40:429-34.

25. Wiklund M, Malmgren-Olsson EB, Ohman A, et al. Subjective health complaints in older adolescents are related to perceived stress, anxiety and gender-a cross-sectional school study in Northern Sweden. BMC Public Health 2012;12:993.
26. Hinz A, Brähler E. Normative values for the hospital anxiety and depression scale (HADS) in the general German population. $J$ Psychosom Res 2011;71:74-8.

27. Papay JP, Spielberger CD. Assessment of anxiety and achievement in kindergarten and first- and second-grade children. J Abnorm Child Psych 1986;14:279-86.

28. M K. The Children's Depression Inventory (CDI). Manual. Toronto, Ontario, Canada: Multi-Health Systems, Inc., 1992.

29. Kovacs M. The Children's Depression, Inventory (CDI). Psychopharmacol Bull 1985;21:995-8.

30. Haywood KL, Staniszewska S, Chapman S. Quality and acceptability of patient-reported outcome measures used in chronic fatigue syndrome/myalgic encephalomyelitis (CFS/ME): a systematic review. Qual Life Res 2012;21:35-52.

31. Haywood KL, Collin SM, Crawley E. Assessing severity of illness and outcomes of treatment in children with chronic fatigue syndrome/myalgic encephalomyelitis (CFS/ME): a systematic review of patient-reported outcome measures (PROMs). Child Care Health Dev 2014;40:806-24.

32. Crawley $\mathrm{E}$, Hughes $\mathrm{R}$, Northstone $\mathrm{K}$, et al. Chronic disabling fatigue at age 13 and association with family adversity. Pediatrics 2012;130: e71-9.

33. Crawley EM, Emond AM, Sterne JA. Unidentified chronic fatigue syndrome/myalgic encephalomyelitis (CFS/ME) is a major cause of school absence: surveillance outcomes from school-based clinics. BMJ Open 2011:1:e000252.

34. Nijhof SL, Maijer K, Bleijenberg G, et al. Adolescent chronic fatigue syndrome: prevalence, incidence, and morbidity. Pediatrics 2011;127:e1169-75.

35. Ghandour RM, Overpeck MD, Huang ZJ, et al. Headache, stomachache, backache, and morning fatigue among adolescent girls in the United States: associations with behavioral, sociodemographic, and environmental factors. Arch Pediatr Adolesc Med 2004;158:797-803. 
Correction: Chronic fatigue syndrome (CFS) or myalgic encephalomyelitis (ME) is different in children compared to in adults: a study of UK and Dutch clinical cohorts

Collin SM, Nuevo R, van de Putte EM, et al. Chronic fatigue syndrome (CFS) or myalgic encephalomyelitis (ME) is different in children compared to in adults: a study of UK and Dutch clinical cohorts. BMJ Open 2015;5:e008830. doi: 10.1136/bmjopen-2015-008830

The "Ethics approval" statement in this article has been amended to read:

Ethics approval: The patient data used in this study were collected as part of routine clinical practice and anonymised for the National Outcomes Database. Under the Governance Arrangements for Research Ethics Committees \{September 2011), ethical review is not required for research limited to the use of previously collected, nonidentifiable patient information.

In addition, the following two sentences have been amended.

- The second paragraph under Strengths and limitations should read "Adults and children were from specialist CFS/ME services in the UK and the Netherlands, so the results may not be generalisable to other settings, such as primary care.

- The second sentence of second paragraph under Discussion should read "Adults and children were from specialist CFS/ME services in the UK and the Netherlands, so the results may not be generalisable to other settings, such as primary care."

Open access This is an open access article distributed in accordance with the Creative Commons Attribution 4.0 Unported (CC BY 4.0) license, which permits others to copy, redistribute, remix, transform and build upon this work for any purpose, provided the original work is properly cited, a link to the licence is given, and indication of whether changes were made. See: https://creativecommons.org/licenses/by/4.0/.

C Author(s) (or their employer(s)) 2019. Re-use permitted under CC BY. Published by BMJ.

BMJ Open 2019;9:e008830corr1. doi:10.1136/bmjopen-2015-008830corr1

Check for updates 